\title{
Comparison of the effectiveness of schema therapy and acceptance and commitment therapy on perception of disease and worry in patients with illness anxiety disorder
}

Recieved: 15 Apr. 2020

Revised: 16 May. 2020

Accepted: 2 Jun. 2020

\section{Keywords}

Schema therapy

Acceptance and commitment therapy

Illness perception

Worry

Illness anxiety disorder

Corresponding author

Bahram Mirzaian, Assistant Professor, Department of Psychology, Sari Branch, Islamic Azad University, Sari, Iran

Email: Bahrammirzaian@gmail.com



\author{
Oldouz Mokhtarinejad ${ }^{1}$, Bahram Mirzaian ${ }^{2 *}$ (D) , Ramezan Hassanzadeh ${ }^{3}$
}

\section{Abstract}

Introduction: One of the topics discussed in psychology is how people respond to physical illnesses. That could lead to many problems. This study aimed to compare the effectiveness of schema therapy and acceptance and commitment therapy on the perception of disease and worry in patients with illness anxiety disorder.

Methods: This was a quasi-experimental study with pre-test and post-test design. A sample of 45 patients with anxiety disorder selected by purposive sampling and divided into two experimental groups (schema therapy and treatment based on acceptance and commitment) and a control group (15 people in each group). Then, 12 sessions of 90-minute schema therapy and 8 sessions of 90-minute therapy based on acceptance and commitment were performed in the experimental groups. The instruments used were the Pennsylvania Worry Questionnaire and Disease Perception Questionnaire. Data were analyzed using multivariate analysis of covariance and univariate analysis of covariance.

Results: The results showed that schema therapy, acceptance and commitment therapy effectively reduced worry and illness perception of patients with anxiety disorder but there was no significant relationship between these two treatments.

Conclusion: Given the role of beliefs and thoughts in anxiety disorder, it is recommended that therapists consider schema therapy and acceptance-based therapy to reduce symptoms of anxiety and illness perception.

Citation: Mokhtarinejad O, Mirzaian B, Hassanzadeh R. Comparison of the effectiveness of schema therapy and acceptance and commitment therapy on perception of disease and worry in patients with illness anxiety disorder. Advances in Cognitive Sciences. 2020;22(3):58-67. 


\title{
مقايسه اثربخشى طر حواره درماذى و درمان مبتنى بر يذيرش و تعهد بر ادراك بيمارى و

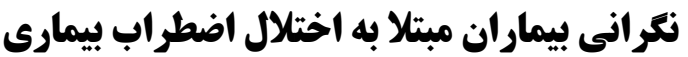

\author{
اولدوز مختارىنزاد'، دكتر بهرام ميرزائيان ‘"(iD) ، دكتر رمضان حسنزاده"
}

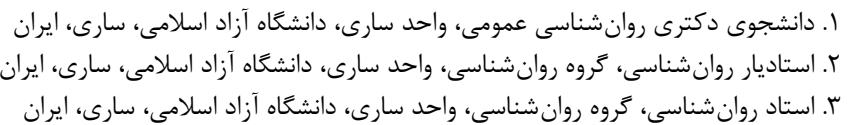

\begin{abstract}
בris همه جانبهاى براى فرد داشته باشد. مطالعه حاضر با هدف مقايسه اثربخشى طرحواره درمانى و درمان مبتنى بر پذيرش و تعهد بر نكرانى و ادراك بيمارى مبتلايان به اختلال اضطراب بيمارى انجام كرفت. روش كار: يروهش حاضر از نوع نيمه آزمايشى با طحح بيشآزمون-يس آزمون سه گروهى بود. نمونهاى به حجم لهأ نفر از بيماران مبتلا به اختلال اضطراب بيمارى به روش نمونه گيرى هدفمند انتخاب و در دو كروه آزمايشى (طرحواره درمانى

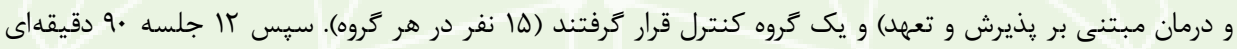
طرحواره درمانى و 1 جلسه •و دقيقهاى درمان مبتنى بر يذيرش و تعهد در كروههاى آزمايشى انجام شد. دادهها با استفاده از يرسشنامه نكرانى پنسيلوانيا و يرسشنامه ادراك بيمارى جمعآورى شد. تجزيه و تحليل دادها با استفاده از آزمون آمارى تحليل كوواريانس با نرمافزار SPSS-21 انجام كرفت. يافته ها: نتايج يُوهش نشان داد كه طرحواره درمانى و درمان مبتنى بر يذيرش و تعهد بر كاهش نكرانى و ادراك بيمارى مبتلايان به اختلال اضطراب بيمارى موثر است (ه•/P> P). اما بين اين دو درمان تفاوت معنادارى وجود نداشت (ه • P> (P). نتيجه كيرى: با توجه به نقش باورها و افكار در اختلال اضطراب بيمارى بيشنهاد مىشود كه درمانكران، طرحواره درمانى و درمان مبتنى بر يذيرش و تعهد را در كاهش علائم نكرانى و ادراك بيمارى مد نظر قرار دهند.
\end{abstract}

دريافت:

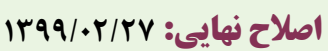



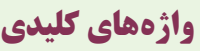
طرحواره درمانى درمان مبتنى بر يذيرش و تعهد نخرانى

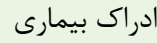

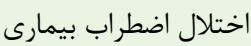

نويسنله مسئول بهرام ميرزائيان، استاديار گروه روانشناسى، واحد سارى، دانشخاه آزاد اسلامى، سارى، ايران

ايميل: Bahrammirzaian@gmail.com

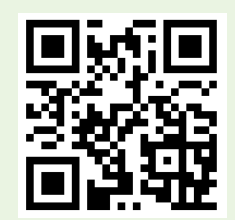

dol doi.org/10.30699/icss.22.3.58

مقدمه

يكى از مباحث مطرح در روانشناسى نحوه واكنش افراد به بيمارىهاى براى زنده ماندن ضرورى است، تعجبآور نيست كه بيشتر مردم نغرانى هايى درباره سلامتى شان داشته باشند. اين افكار و نغرانى ها در مرور جسمانى است. در يك سو كسانى قرار دارند كه به انكار مشكلات ميان افرادى كه به بيمارى وخيمى مبتلا هستند و يا در معرض خطر جسمانى خود مى يردازند و در سوى ديگر كسانى قرار دارند كه ابتلا به يك نوع بيمارى خاص مى باشند مى تواند بيشتر باشد. اما افرادى نشانهاى جزئى و حتى خوش خيمى جسمانى را نشانه بيمارى و خيم هستند كه بدون اين كه در معرض خطر و يا مبتلا به بيمارى خاصى جسمانى سوءتعبير مى كنند (1). با توجه به اين كه سلامت جسمانى 
و مدت زمان بيمارى تنظيم مىنمايند (1). درك از بيمارى V حيطه هويت (درك علائم بيمارى)، سير بيمارى (مزمن يا حاد بودن)، بِيامد بيمارى، كنترل فردى، كنترل درمانى، كنار آمدن با بيمارى، دورهاى

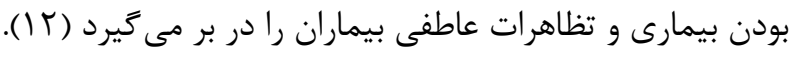



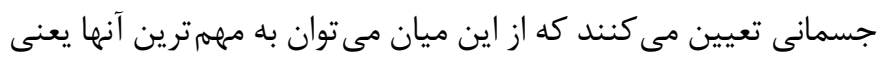
معنايى كه فرد به نشانههاى خود مى دهد، اشاره كرد. باورهاى ناكار آمد يا طرحوارههاى ناسازگار اوليه كه زرفترين ساختارهاى شناختى، هستند بر كارآمدى هيجانى و رفتارى تاثير مى گذارند. طرحوارهها در رويارويى با محركهاى جديد بر يايه ساختار پيشين خود، اطلاعات

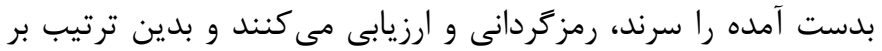
نوع نكرش افراد نسبت به خود و جهان پِيرامونشان تاثير مى كذارند. در

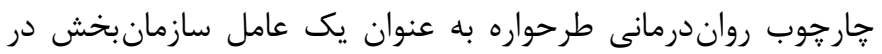

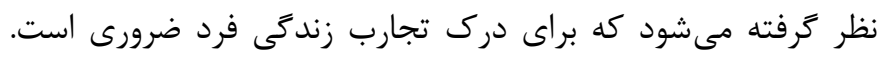

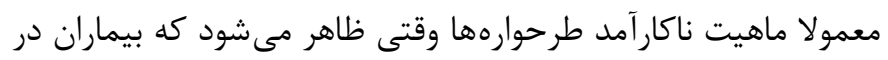
روند زندگى روزمره خود و در تعامل با ديخران به كونهاى عمل كنداند

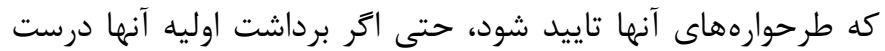
نباشد (r ()). در بين افراد با سطوح ترس ادراك شده از بيمارى، تجارب منفى زندگى در فراخوانى الكوهاى هيجانى منفى بعدى مؤثرتر است. در مقابل، در بين افراد با سطوح ترس ادراك شده يايين، تغييرات منفى زندكى بر الكوى تجارب هيجانى منفى بعدى اثر اندكى دارند. اين وضعيت در بين افراد با سطوح ترس ادراك شده بالا، از طريق بدايق

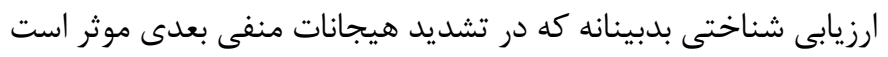

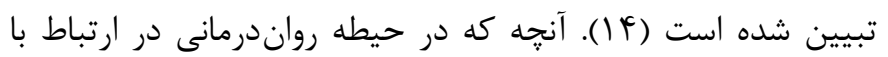
طرحوارهها مهمم است، اين عقيده است كه اكثر طرحوارهها در سال هاى

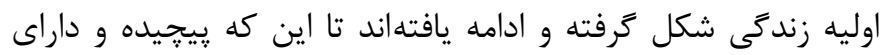
جزئيات فراوان شدهاند، و سيس روى تجارب بعدى زندكى آن جنان اثر كذاشتهاند كه ديخر هيج تجربهاى بدون دخالت آنها ممكن نيست. به اين ترتيب به دليل نياز به (انسجام شناختى" و جهت حفظ ديدكاه ثابتى از خود و دنيا به استفاده از طرحوارهها (حتى اكر هم نادرست و

تحريف شده باشند)، روى مى آورند (هاد). درمانهايى مختلفى در دو دهه اخير در كاهش استرس و اضطراب

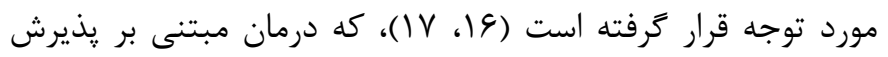

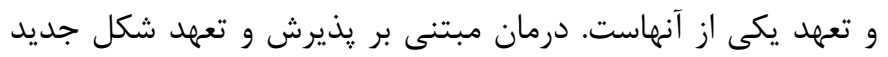

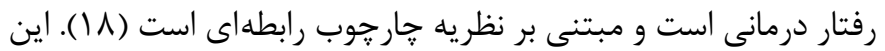
رويكرد در مقايسه با رفتار درمانى شناختى تاكيد بيشترى بر يذيرش و

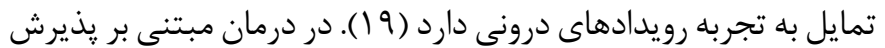

باشند دجار نكَرانى و اضطراب شديدى نسبت به سلامتىشان مىشوند و علائم جسمانى ساده را به عنوان بيمارى وخيم تلقى مى كنند. اين افر اد دجار اضطراب سلامتى مى باشند (Y). اضطراب سلامت كه اختلال اضطراب بيمارى (Illness anxiety disorder) نيز ناميده مى شود در

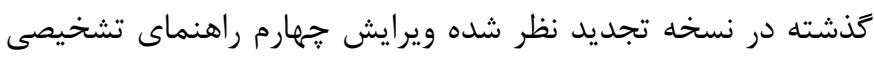
و آمارى اختلالهاى روانى (Diagnostic and Statistical Manual) of Mental Disorders-IV-TR شناخته مىشد (r). بر اساس ملاكهاى (Hypochondriasis)

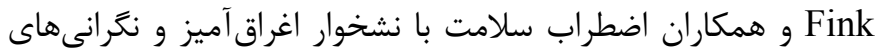
مكرر در مورد بيمارىهاى جدى و اشتغال ذهنى مداوم كه موجب اختلال در سلامت روان و كاهش كيفيت زندگى مىشود، مشخص مىشود. اضطراب سلامتى يعنى ترس مداوم از اين كه يى ببريد به بيمارى خطرناكى مبتلا خواهيد شد. در حالى كه مىتوانستيد جلوى

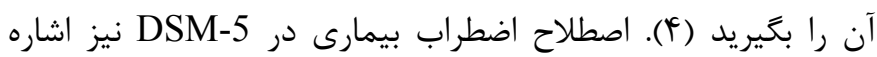
به ملاكهاى مشابه مطرح شده توسط Fink را دارد. بيماران دجار

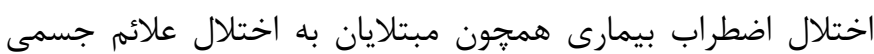
معتقدند كه مبتلا به يك بيمارى وخيم (Somatoform disorder) هستند كه هنوز تشخيص داده نشدند و نمى توان آنها را به قبول خلاف اين موضوع قانع كرد. اعتقاد آنها به وجود بيمارى عليرغم نتايج منفى آزمايشات، سير خوشخيم بيمارى فرضى در طول زمان و اطمينان بخشى مناسب از سوى يزشكان همجنان ادامه مى يابد. اشتغال ذهنى

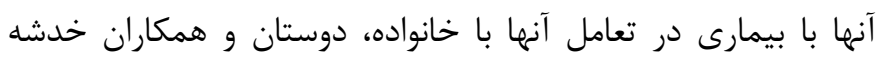

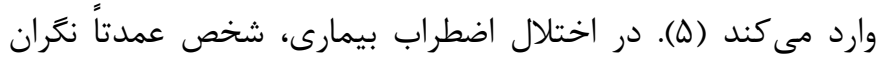

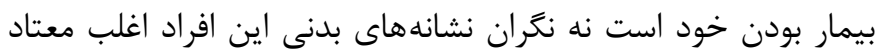
به جستجوهاى اينترنتى در مورد بيمارى فرضى هستند و از اطلاعاتى

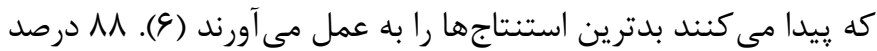

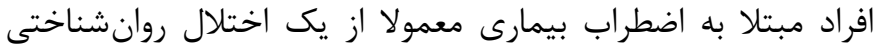
ديخر نيز رنج مىبرند. به ويزه افسردگى، اضطراب فراگير يا شكايات جسمانى (V). شواهد تجربى نشان مى دهد كه افراد دجار اختلال

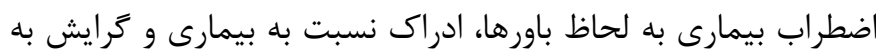

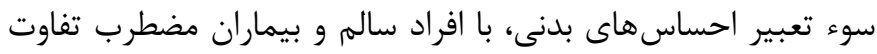
دارند (1). علاوه بر اين بيشتر اين افراد مانند بيماران مبتلا به اختلال


هستند (^، 9). منظور از ادراى بيمارى (Illness perception)، بازنمايى شناختى سازمان يافته بيمار از بيمارى خود مىباشد (• (). بر ادرال اساس نظريه Leventhal، بيماران رفتار و واكنش هيجانى خود نسبت به بيمارى را بر اساس ادراك خود از ماهيت، علل، ييامد، كنترل يذيرى 
لازم در خصوص برگزارى دوره آموزشى صورت گرفت. قبل شروع

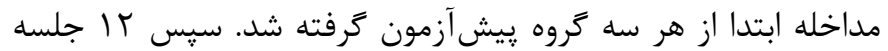

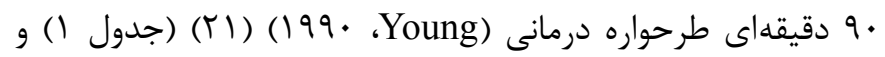

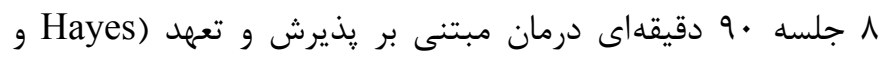

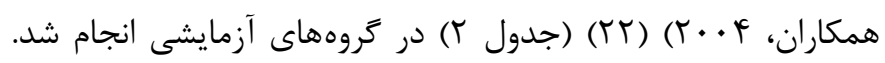

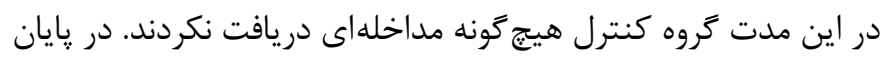

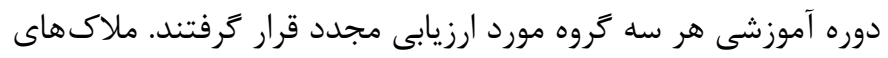

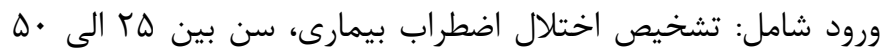

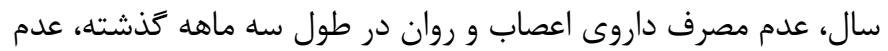
ابتلا به بيمارى جسمانى جدى مانند سرطان، MS، آلزايمر و نظير

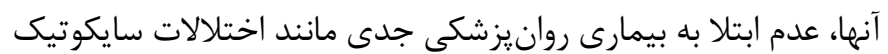
و.... داشتن سواد حداقل تا سوم راهنمايى، تكميل موافقتنامه رضايت

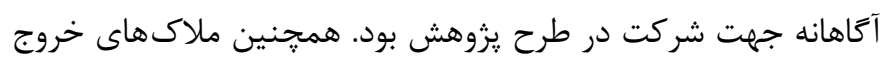

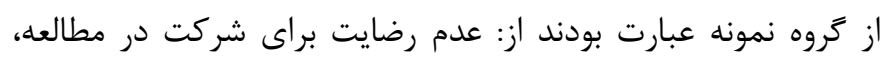

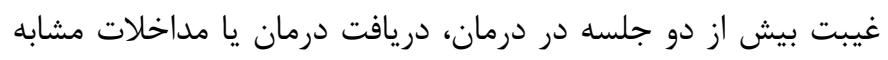

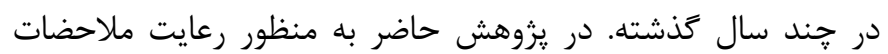

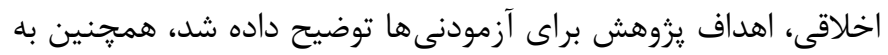
تمام شركت كنندكان اين اطمينان داده شد كه اطلاعات آنان محرمانه خواهد بود. اگر بيمارى تمايل به حضور در مطالعه نداشت، وارد مطالعه

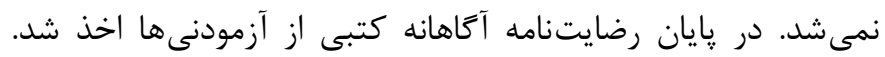

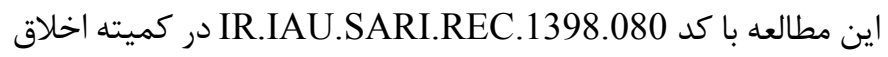
دانشگاه آزاد اسلامى واحد سارى مورد بررسى و تاييد قرار كرفته

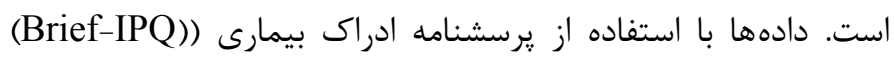
Brief Illness Perception Questionnaire

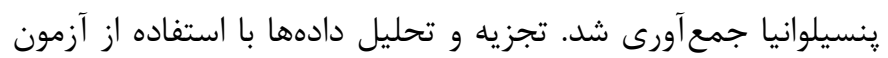


يرسشنامه ادراك بيمارى (Brief-IPQ): اين برسشنامه 9 سؤالى برأى براى ارزيابى تجسم عاطفى و شناختى بيمارى طراحى شده است

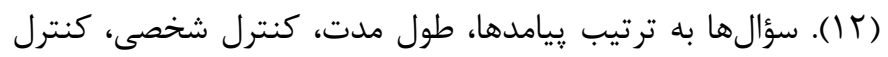

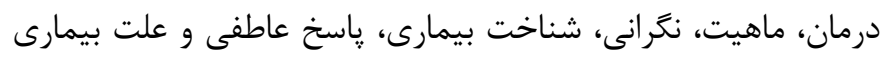

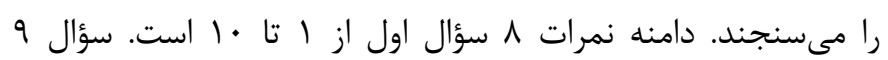

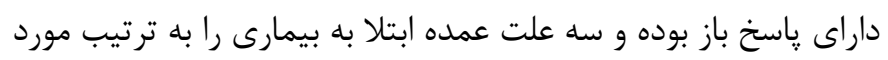

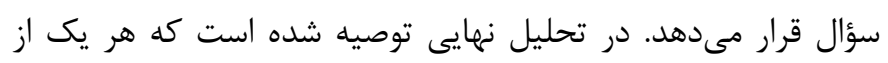

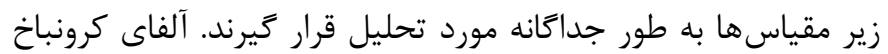

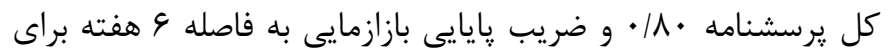

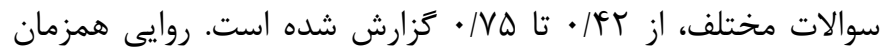
مقياس با ترسشنامه ادراى بيمارى تجديدنظر شده نشاندهنده
و تعهد فرض بر اين است كه انسانها بسيارى از احساسات، هيجانات يا

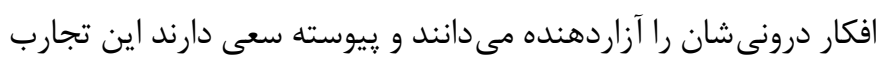

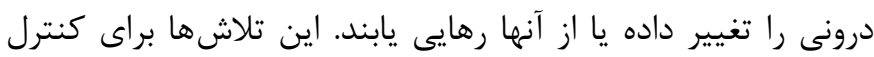

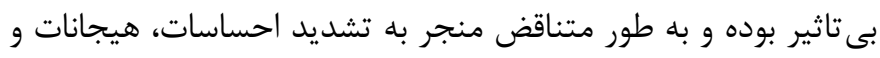

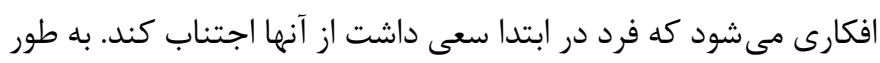

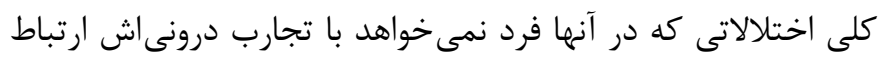

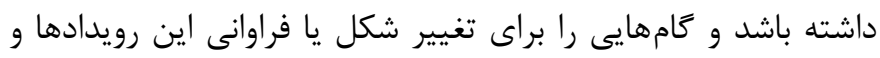

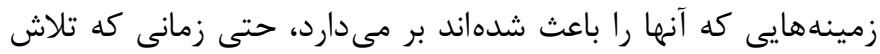
براى جنين كارهايى تاثيرى منفى بر كيفيت زندگى اش دارد، اجتناب تجربهاى ناميده مى شوند. درمان مبتنى بر يذيرش و تعهد شش فرايند



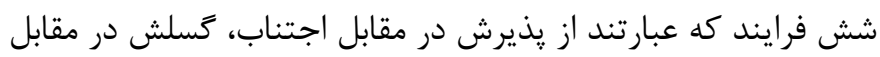

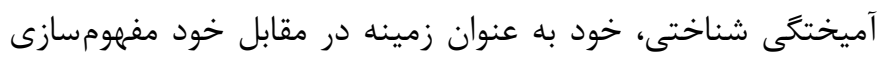

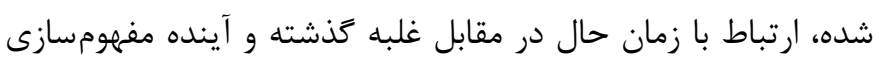

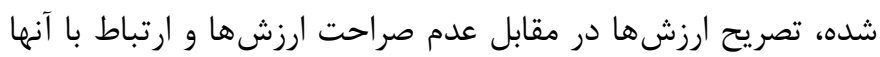

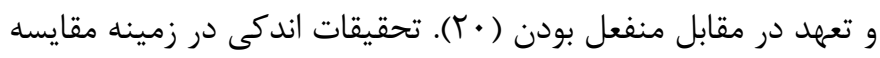

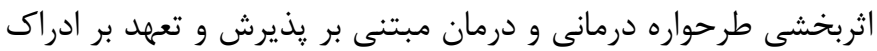

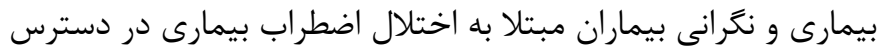

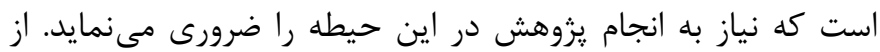

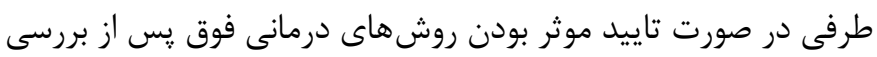

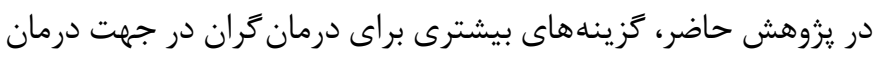

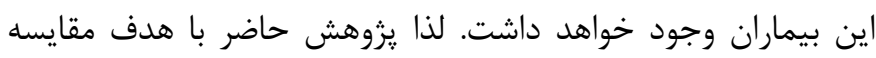

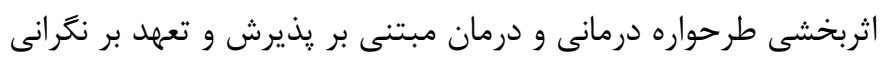

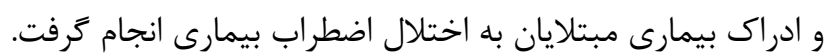

\section{روش كار}

اين يزوهش از نوع نيمه آزمايشى با طرح پيش آزمون_يس آزمون با سه كروه بود. جامعه اين يزوهش شامل افرادى بود كه به مراكز مشاوره



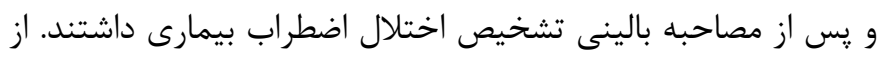

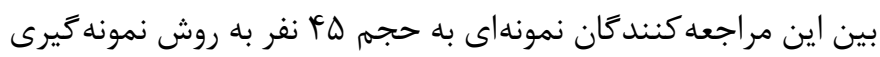

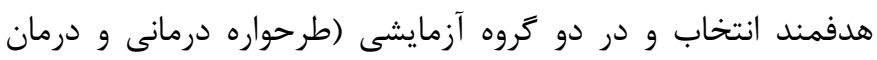

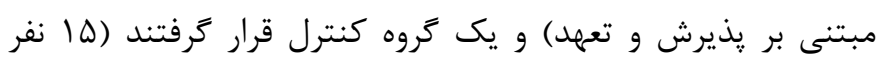

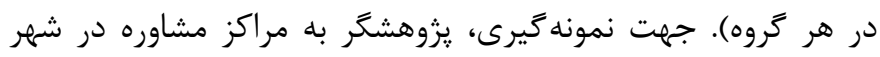
سارى مراجعه كرده و بعد از هماهنكى با مراكز مورد نظر، اطلاعيه در



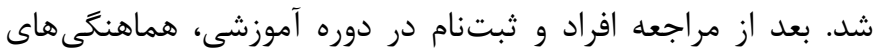


تا ه=بسيار زياد در مورد من صادق است رتبهبندى مىشود (YF).

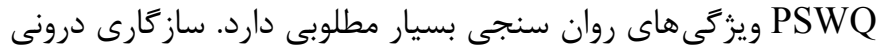
ضريب آلفا براى اين ابزار 94/ • عزارش شده و از نظر روايى نيز اين ابزار به خوبى مى تواند بيماران مبتلا به اختلال اضطراب فراگير را از بيماران افسرده جدا كند. افزون بر اين، روايى سازهاى اين ابزار در بررسىهاى تحليل عاملى به تأييد رسيده است (YF). در ايران دهشيرى و همكاران در مطالعهاى به بررسى خصوصيات روانسنجى يرسشنامه نخرانى ايالت ينسيلوانيا بر روى يك نمونه FYF نفرى : يرداختند. نتايج آنها حاكى از بالا بودن ضرايب همسانى درونى و بازآزمايى (با فاصله يك ماه) بود. همجنين همبستكى معنادارى بين نمرات يرسشنامه با نمرات اضطراب

صفت و افسردگى بود (ها).
همبستخى زيرمقياسها از rس// تا سع|• است (r)). در ايران باقريان و همكاران نسخه فارسى اين مقياس را تهيه نمودهاند. آلفاى كرونباخ نسخه فارسى Af| • و ضريب همبستخى آن با نسخه فارسى يرسشنامه ادراك بيمارى تجديدنظر شده VI/ • ₹زارش نمودهاند (YM). Worry Questionnaire (PSWQ)) يرسشنامه نكرانى «نسيلوانيا Pennsylvania State) اين : يرسشنامه در سال •199 توسط Barlow و ساخته شده است و يك ابزار خودسنجى 19 و سوالى است كه نگرانى شديد، مفرط و غير قابل كنترل را اندازهيرى مى كند. اين مادهها براى دستيابى به ابعاد عموميت، شدت و كنترلنايذيرى نخرانى مرضى طراحى شدهاند. هر ماده روى يك مقياس ليكرتى له درجهاى بين |=به هيج وجه در مورد من صادق نيست

جدول 1. خلاصه محتواى جلسات طرحواره درمانى

خلاصه جلسات

جلسات

آشنايى اعضاى گروه، ايجاد يك رابطه متقابل و برخوردار از تشريك مساعى، آموزش رويكرد طرحواره درمانى، اخذ رضايتنامه آكاهانه، ارايه آزمون هاى يُوهش

جلسه اول

سنجش مشكلات بيمار، ارزيابى سبك هاى مقابلهاى، ضابطهبندى مشكل مراجعان بر اساس رويكرد طرحواره محور و تكميل فرم مفهوميردازى

جلسه دوم

استفاده از روش هاى شناختى در جهت ترديد و بىاعتبارسازى طرحوارههاى غالب مراجعان

جلسه سوم تا ينجم

استفاده از روش هاى تجربى در جهت آشنايى مراجع با ريشههاى تحولى طرحوارهها و درى راهكارهاى ناساز كارانه ارضاى نيازهاى هيجانى جلسه ششم تا هشتم تشويق و ترغيب مراجع در جهت رها كردن سبكهاى مقابلهاى ناساز كار و تمرين رفتارهاى مقابلهاى سازحارانه براى ارضا و تشفى نيازهاى هيجانى اساسى، و وادار داشتن بيمار به آماده ساختن فهرستى از مهارتهاى آموخته شده در درمان و ييشكيرى از عود جلسه نهم تا دوازدهم

جدول r. خلاصه محتواى جلسات درمان مبتنى بر يذيرش و تعهد

\section{خلاصه جلسات}

آشنايى اعضاى گروه با يكديگر و با رهبر، نام كذارى براى گروه، بيان خار هوب اساسى برنامه كار و اهداف جلسات، انجام ييشآزمون

مرورى اجمالى بر مباحث جلسه قبل، مزايا و معايب و شيوههاى كنترل مشكلات، ارائه تكليف

بررسى تكليف جلسه قبل، تصريح ناكارآمدى كنترل رويدادهاى منفى با استفاده از استعارهها و آموزش تمايل نسبت به هيجانات و تجارب منفى برى

بررسى تكليف جلسه قبل، آموزش جدا كردن ارزيابىها از تجارب شخصى و اتخاذ موضع مشاهده افكار

$$
\text { بدون قضاوت }
$$

بررسى تكليف جلسه قبل، ارتباط با زمان حال و در نظر كرفتن خود به عنوان زمينه (استعاره صفحه شطرنج) و آموزش فنون ذهن آكاهى
هدف

جلسات

استخراج تجربه اجتناب،

آميختكى و ارزش ACT

جلسه اول

مزايا و معايب و شيوه هاى

كنترل مشكلات

جلسه دوم

كنار كذاشتن شيوه هاى

ناكار آمد كنترل

جلسه سوم

مشاهده و عدم ارزيابى

تجارب و هيجانات

جلسه جهارم

نظاره افكار با استفاده از

فنون ذهن آتَاهى 
بررسى تكليف جلسه قبل، شناسايى ارزشهاى زندكى بيماران و سنجش ارزشها بر مبناى ميزان موانع بيش روى در

اهميت آنها

تحقق ارزشها

جلسه ششم

بررسى تكليف جلسه قبل، ارايه راهكارهاى عملى در رفع موانع ضمن به كارگيرى استعارهها و برنامه ريزى

$$
\text { براى تعهد نسبت به يِيَيرى ارزشها }
$$

درخواست از اعضا براى توضيح دستاوردهايشان از كروه و برنامه آنها براى ادامه زندكى و در انتها كرفتن

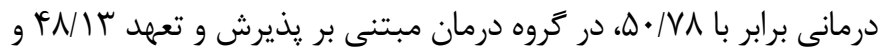

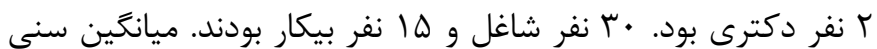

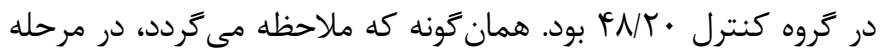
آزمودنى ها ها سال بود. ييشآزمون ميانخين هاى متغيرهاى يزوهش در سه گروه تقريباً با هم برابرند. جدول ب نشان مىدهد كه ميانگين نمرات آزمودنىها در ييشآزمون

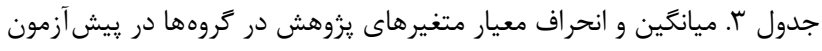

\begin{tabular}{|c|c|c|c|c|c|c|}
\hline \multicolumn{2}{|c|}{ كنترل } & \multicolumn{2}{|c|}{ درمان مبتنى بر يذيرش و تعهد } & \multicolumn{2}{|c|}{ طرحواره درمانى } & \multirow{2}{*}{ مَروه } \\
\hline انحراف معيار & ميانگين & انحراف معيار & ميانگين & انحراف معيار & ميانگين & \\
\hline $11 / \pi 99$ & r & $1 \cdot|\Lambda| f$ & $\Delta \cdot \pi$ & $1 \cdot / 1 \Delta \Delta$ & س & ادراى بيمارى \\
\hline $\mathrm{V} / \cdot \wedge \mathrm{r}$ & $\boldsymbol{F} \wedge / \mathrm{r}$ & II/ATt & FN/IT & $11 / \uparrow \wedge \Lambda$ & $\Delta \cdot / \wedge \vee$ &  \\
\hline
\end{tabular}

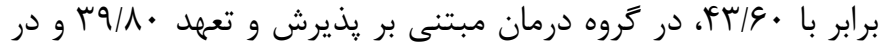
گروه كنترل • FV/\& بوده است. با توجه به يافته باى بدست آمده بين ميانگينهاى متغيرهاى يزوهش در سه گروه تفاوت معنادارى وجود
همان طور كه از اطلاعات جدول f بر مى آيد، ميانگين نمرات يس آزمون ادراك بيمارى در گروه طرحواره درمانى برابر با س س/هأ، در گروه درمان

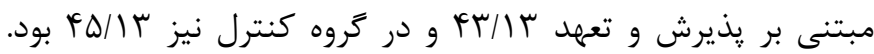
همجنين ميانگين نمرات يسآزمون نَرانى در گروه طرحواره درمانى

جدول أ. ميانگَين و انحراف معيار متغيرهاى يزوهش در تروهها در يس آزمون

\begin{tabular}{|c|c|c|c|c|c|c|}
\hline \multicolumn{2}{|c|}{ كنترل } & \multicolumn{2}{|c|}{ درمان مبتنى بر يذيرش و تعهد } & \multicolumn{2}{|c|}{ طرحواره درمانى } & \multirow{2}{*}{ شروه } \\
\hline انحراف معيار & ميانكين & انحراف معيار & ميانغين & انحراف معيار & ميانكين & \\
\hline $11 / \pi q 4$ & $F \Delta / 1 T$ & $9 / 1 V T$ & r & 9/V५४ & FQ/TK & ادراك بيمارى \\
\hline V/AST & FV/G. & $1 . / 9 V \Delta$ & $r q / \Lambda$. & $11 / \cdot \Delta V$ & Fr/s. & نعَرانى \\
\hline
\end{tabular}

آن جهت بررسى اين كه كدام دو گروه با هم تفاوت دارند از آزمون تعقيبى فيشر استفاده شد، نتايج اين آزمون نشان داد تفاوت هر كدام از گروههاى
نتايج آزمون تحليل كوواريانس نشان داد كه ادراك بيمارى يس ازمداخلههاى




طرحواره درمانى و درمان مبتنى بر يذيرش و تعهد با گروه كنترل معنادار است اما بين نتايج دو نوع درمان تفاوت معنادارى وجود ندارد. جدول ه. نتايج آزمون تحليل كوواريانس براى متغير ادراك بيمارى

\begin{tabular}{|c|c|c|c|c|c|c|}
\hline مجذور اتا & $\mathbf{P}$ & $\mathbf{F}$ & ميانگين مجذوررها & درجه آزادى & مجموع مجذورها & \\
\hline.$/ \Delta 1 \Delta$ & $\cdot \cdots \cdot 1$ & rI/NGY & ISV/TAD & r & $r r F / Q V$. & كروه \\
\hline \multirow[t]{3}{*}{.$/ 9 T V$} & $\cdot 1 \cdots 1$ & $\Delta r I / I \cdot F$ & $\psi \cdot \Delta / \xi \psi$. & 1 & $\psi \cdot \Delta / \xi \psi$. & ييش آزمون \\
\hline & & & V/GAV & il & MIQ//G. & خطا \\
\hline & & & & id & $q 481 \cdot 1 .$. & كل \\
\hline
\end{tabular}

فيشر استفاده شد كه نتايج آن نشان داد تفاوت هر كدام از كروههاى

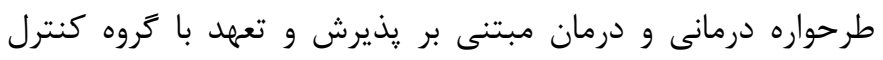

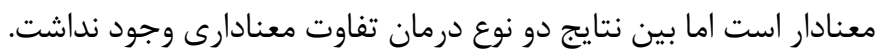

همانطور كه از نتايج حذارش شده در جدول عاز آزمون تحليل واريانس

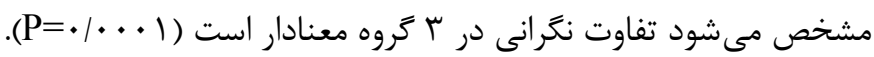
براى اين كه بدانيم كدام دو كروه با هم تفاوت دارند از آزمون تعقيبى

جدول 9. نتايج آزمون تحليل واريانس براى متغير نكرانى

\begin{tabular}{|c|c|c|c|c|c|c|}
\hline مجذور اتا & $\mathbf{P}$ & $\mathbf{F}$ & ميانغين مجذور ها & درجه آزادى & مجموع مجذورها & \\
\hline$\cdot / r v$ & $\cdot|\cdots|$ & $\mid r / \cdot \Delta T$ & $r \Delta F / q Y F$ & r & $0.9 / 9+\lambda$ & تروه \\
\hline \multirow[t]{3}{*}{. /vav } & $\cdot \mid \cdots \cdot$ & $|9 \cdot| \Delta r \mid$ & rrवg/T.। & 1 & r & ييش آزمون \\
\hline & & & $r I / / \Delta \varphi$ & il & $\wedge \vee \vee / \% 99$ & خطا \\
\hline & & & & is & $q \cdot \Delta r \Delta / \cdots$ & كل ل \\
\hline
\end{tabular}

نيز بى فايده بودن ساير راهبردهاى بيمار از قبيل اطمينانجويى مفرطو وارسى مكرر را نيز مشخص مى سازد. اين درمان مشكلات روانشناختى

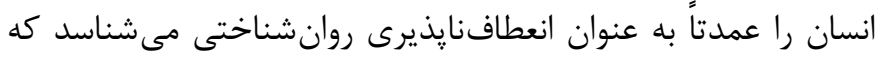
توسط همجوشى شناختى و اجتناب تجربهاى ايجاد شده است. ACT

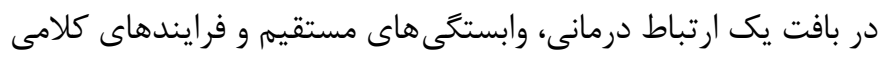

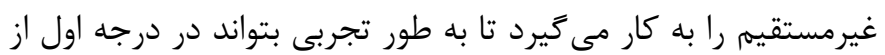
طريق يذيرش، ناهمجوشى، ايجاد يك حس فراتجربى از خود، ارتباط با لحظه اكنون، ارزش ها و ساختن الكوهاى خوب از اقدامات متعهدانه

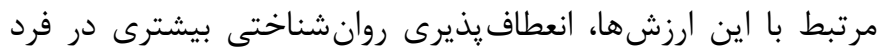
ايجاد كند (Tr). راهبردهاى ناهمجوشى موجب كاهش تاثيرات زيانبار زبان و شناخت مى شوند. همجوشى شناختى زمانى رخ مى ده دهد كه افكار

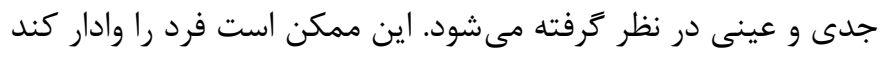

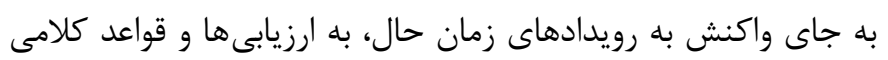

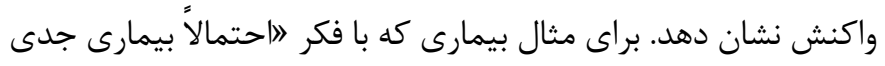

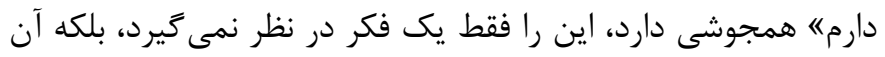

يزوهش حاضر با هدف بررسى اثربخشى طرحواره درمانى و درمان

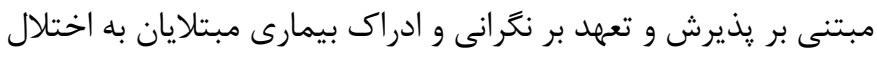

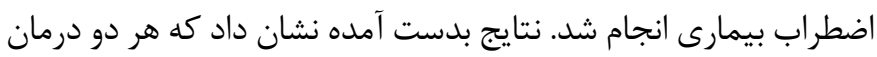

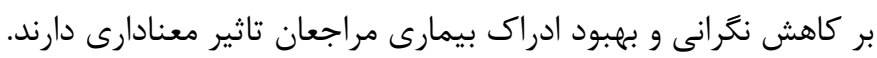
اما در مقايسه ميزان اثربخشى دو درمان تفاوت معنادارى حاصل وجود برداني

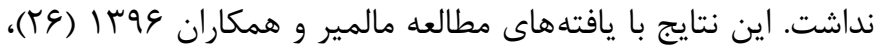

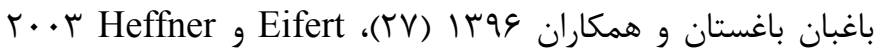

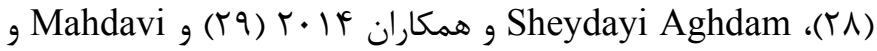

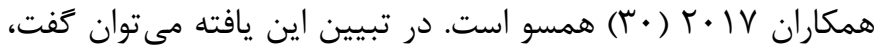

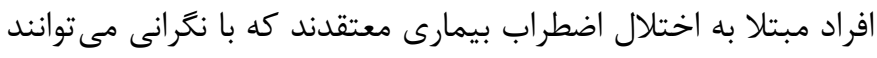

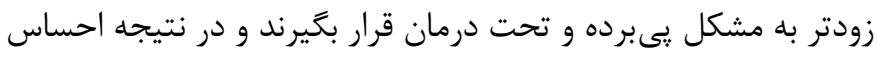

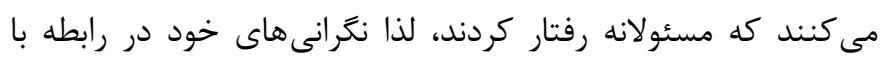

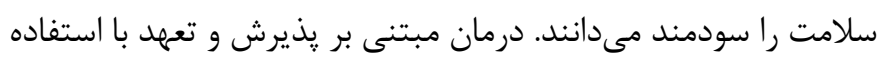

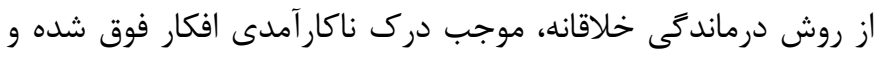


روانى در كنار آمدن افراد با موقعيتهاى مترقبه مفيد هستند. بنابراين اكر بتوان طرحوارههاى افراد مبتلا به اضطراب بيمارى را با استفاده از

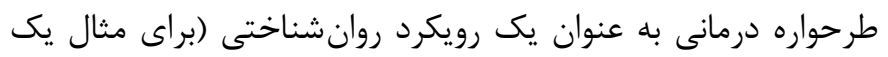

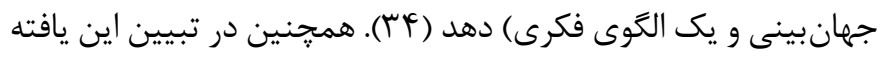

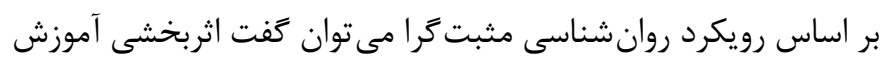

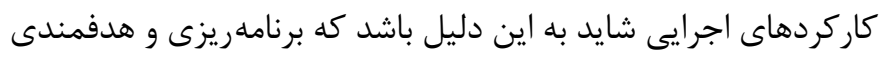

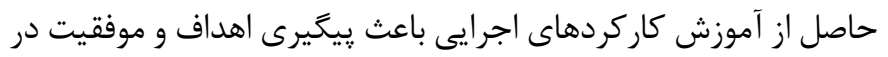

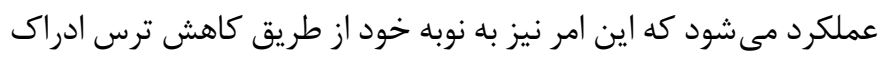

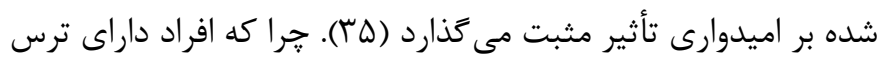

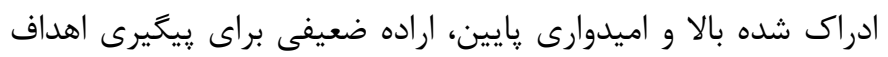

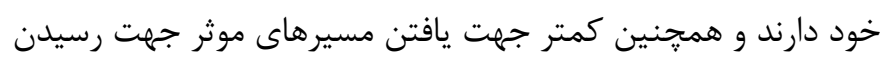

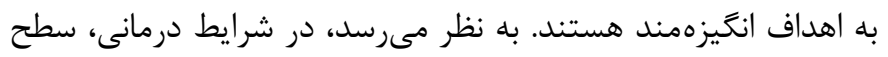

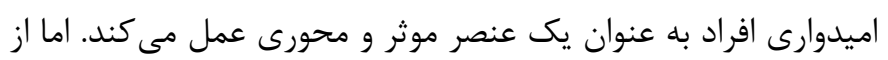
طرفى او براى اين تغيير نيازمند آن است كه با ديدى مثبت به به تغييرات

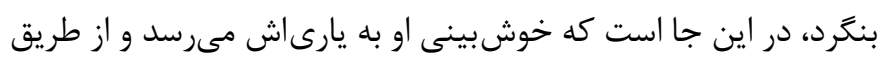

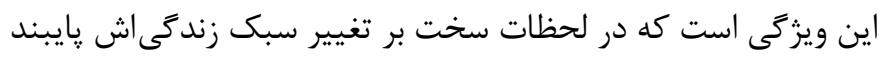

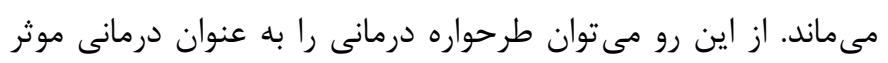

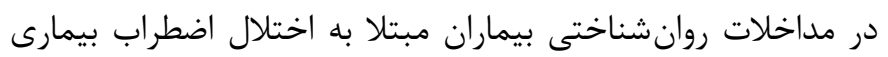

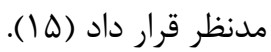

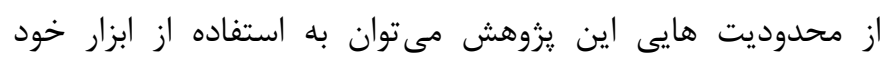

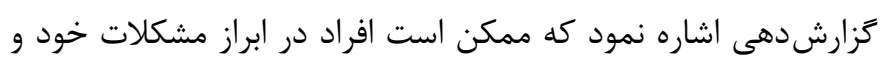

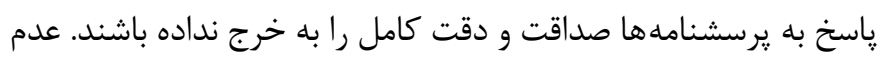
وجود مرحله پيخيرى و در نتيجه در دست نبودن اطلاعاتى از تداوم

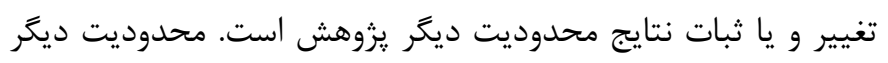

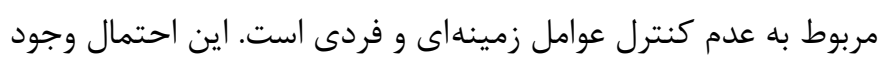

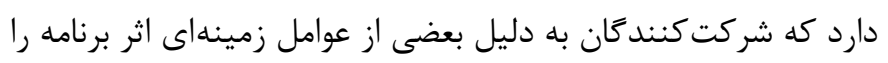

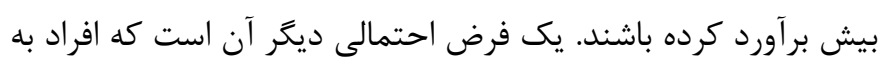

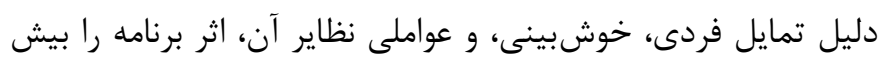

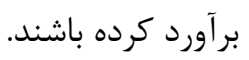

\section{نتيجه كَيرى}

نتايج يزوهش نشان داد كه طرحواره درمانى و درمان مبتنى بر بذيرش

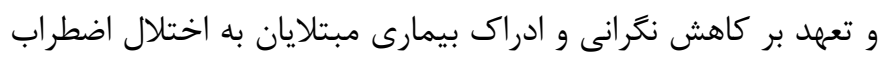

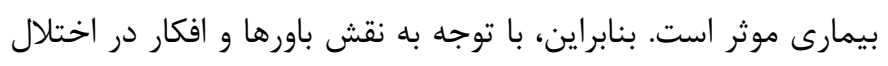

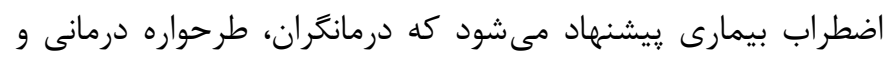

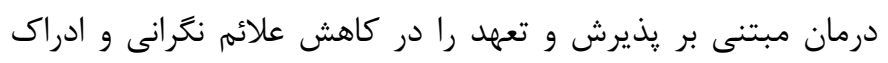
بيمارى مد نظر قرار دهند.

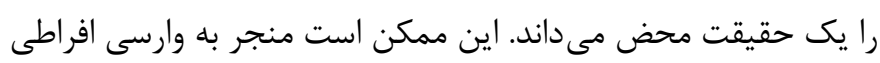

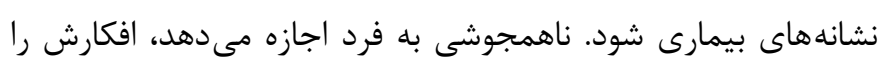

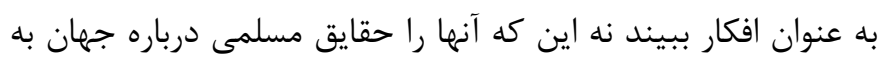

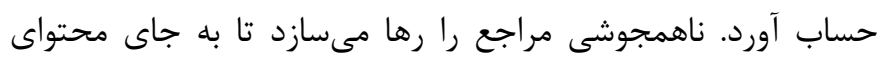
كلامى همجوشى، بر مبناى ارزشها و شرايط محيط كنونى است است عمل رهل

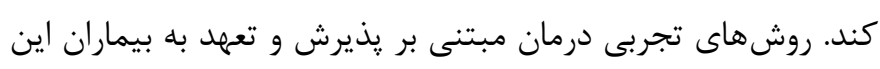

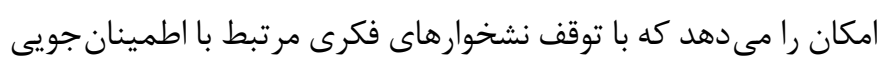

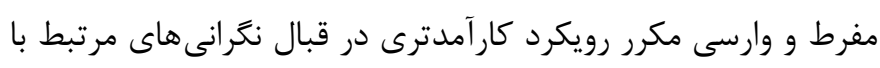

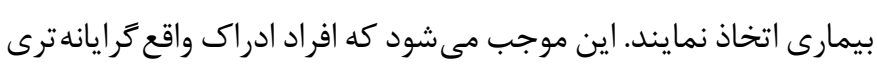

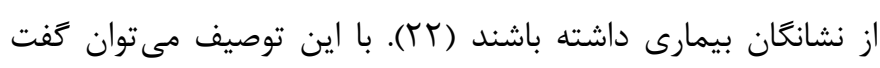

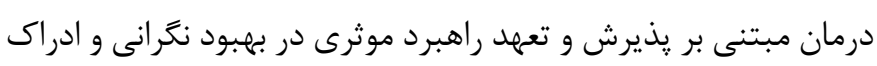

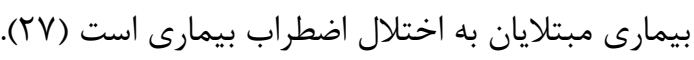

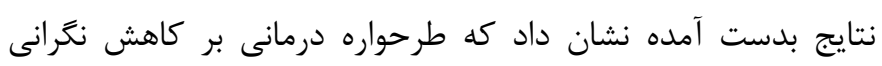

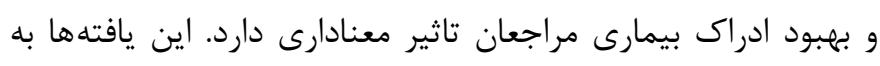
وجود رابطه بين علائم سلامت روان و طرحوارههاى ناسازگًار اوليه

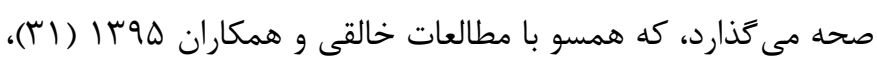

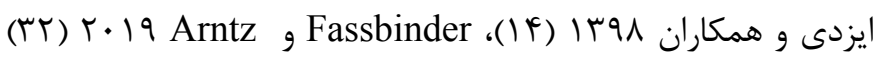
و قربان على يور و همكاران عوسا (سب) است. در تبيين اين يافته

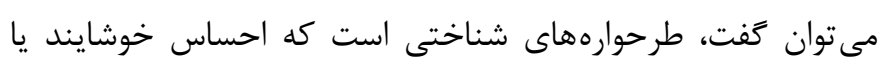

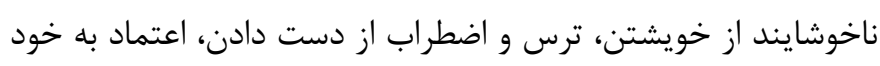

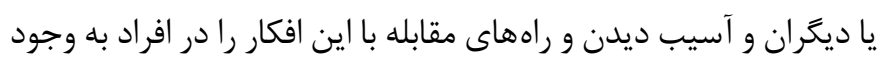

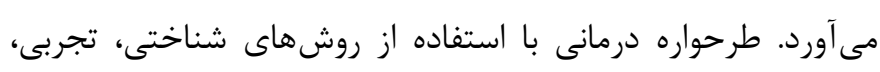
الكَوشكنى رفتارى و رابطه درمانى با ايجاد آكاهى شناختى به به بيماران

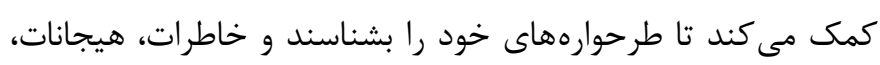

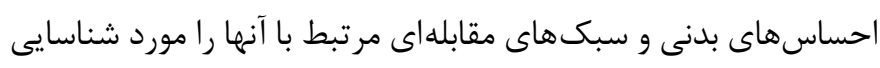

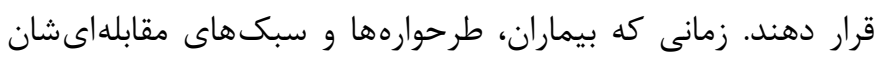

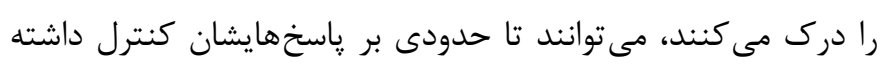

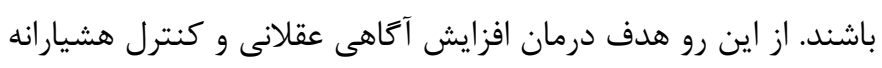

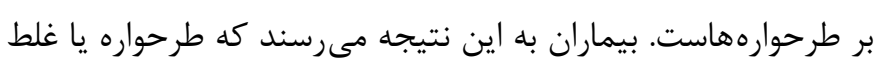

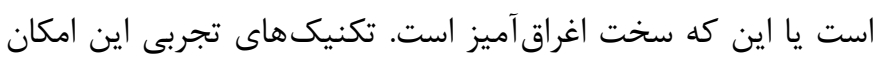
را به بيمار مى دهند كه به ارتباط بين ريشه بهاى تحولى اين اين طر حوارهها

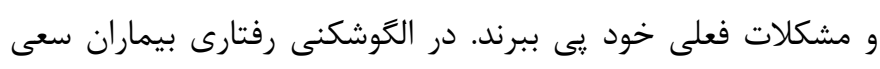

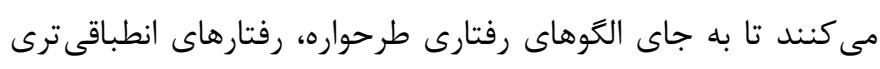

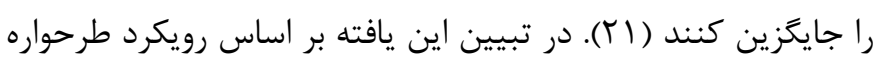

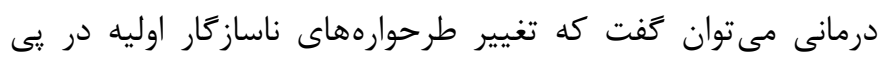

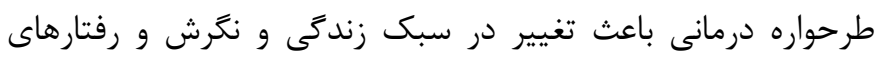

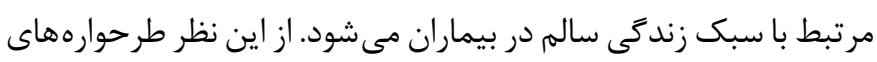




$$
\begin{aligned}
& \text { در دانشخاه آزاد اسلامى واحد سارى مىباشد. بدين وسيله از مساعدت كليه } \\
& \text { عزيزانى كه در انجام اين يزوهش همكارى نمودند، قدردانى مى دمائيمها. }
\end{aligned}
$$

 \\ اين مقاله بركرفته از يايان نامه جهت اخذ PhD رشته روانشناسى عمومى
}

\section{References}

1. Fergus TA. Health-related dysfunctional beliefs and health anxiety: Further evidence of cognitive specificity. Journal of Clinical Psychology. 2014;70(3):248-259.

2. Melli G, Bailey R, Carraresi C, Poli A. Metacognitive beliefs as a predictor of health anxiety in a self-reporting Italian clinical sample. Clinical Psychology \& Psychotherapy. 2018;25(2):263271.

3. Association AP. Diagnostic and statistical manual of mental disorders (IV-TR). Washington, DC:American Psychiatric Publication;2000.

4. Fink P, Ornbol E, Christensen KS. The outcome of health anxiety in primary care. A two-year follow-up study on health care costs and self-rated health. PloS One. 2010;5(3):e9873.

5. Association AP. Diagnostic and statistical manual of mental disorders (DSM-5®). Arlington VA:American Psychiatric Publication;2013.

6. DiBartolo PM, Frost RO, Dixon A, Almodovar S. Can cognitive restructuring reduce the disruption associated with perfectionistic concerns?. Behavior Therapy. 2001;32(1):167-184. 7. Leahy RL. The worry cure: Seven steps to stop worry from stopping you. 1st ed. New York: Harmony;2006.

8. Yazdi-Ravandi S, Shamsaei F, Matinnia N, Shams J, Moghimbeigi A, Ghaleiha A, et al. Cognitive process in patients with obsessive-compulsive disorder: A cross-sectional analytic study. Basic and Clinical Neuroscience. 2018;9(6):448-457.

9. Yazdi-Ravandi S, Shamsaei F, Matinnia N, Moghimbeigi A, Shams J, Ahmadpanah M, et al. Executive functions, selective attention and information processing in patients with obsessive compulsive disorder: A study from west of Iran. Asian Journal of Psychiatry. 2018;37:140-145.

10. Indrayana S, Guo S-E, Lin C-L, Fang S-Y. Illness perception as a predictor of foot care behavior among people with type 2 diabetes mellitus in Indonesia. Journal of Transcultural Nursing. 2019;30(1):17-25.

11. Leventhal H, Meyer D, Nerenz D. The common sense representation of illness danger. In: Rachman S, editor. Medical psychology. New York:Pergamum Press;1980. pp. 7-30.

12. Broadbent E, Petrie KJ, Main J, Weinman J. The brief illness perception questionnaire. Journal of Psychosomatic Research. 2006;60(6):631-637.

13. Rafaeli E, Bernstein DP, Young J. Schema therapy: Distinctive features. 1st ed. New York:Routledge;2010.

14. Izadi F, Ashrafi E, Fathi Ashtiani A. The effectiveness of emotional schema therapy on reduction of the negative emotional schemas, alexithymia and signs of patients with somatic symptoms. Journal of Behavioral Sciences Research. 2019;17(2):232-243. (Persian)

15. Bach B, Bernstein DP. Schema therapy conceptualization of personality functioning and traits in ICD-11 and DSM-5. Current Opinion in Psychiatry. 2019;32(1):38-49.

16. Azami E, Hajsadeghi Z, Yazdi-Ravandi S. The comparative study of effectiveness of training communication and emotional skills on parenting stress of mothers with autism children. Zanko Journal of Medical Sciences. 2017;18(56):1-11. (Persian)

17. Hajsadeghi Z, Yazdi-Ravandi S, Pirnia B. Compassion-focused therapy on levels of anxiety and depression among women with breast cancer: A randomized pilot trial. International Journal of Cancer Management. 2018;11(11):e67019.

18. Biglan A, Hayes SC, Pistorello J. Acceptance and commitment: Implications for prevention science. Prevention Science. 2008;9(3):139-152.

19. Gaudiano BA, Herbert JD. Acute treatment of inpatients with psychotic symptoms using acceptance and commitment therapy: Pilot results. Behaviour Research and Therapy. 
2006;44(3):415-437.

20. Hayes SC. Acceptance and commitment therapy, relational frame theory, and the third wave of behavioral and cognitive therapies-republished article. Behavior Therapy. 2016;47(6):869-885.

21. Young JE, Klosko JS, Weishaar ME. Schema therapy: A practitioner's guide. New York:Guilford Press;2003.

22. Hayes SC, Strosahl KD, Bunting K, Twohig M, Wilson KG. What is acceptance and commitment therapy.? In: Hayes SC, Strosahl KD, editors. A practical guide to acceptance and commitment therapy. Boston, MA:Springer;2004. pp. 3-29.

23. Bagherian Sararudi R, Bahrami E, Sanei H. Relationship between history of myocardial infraction and cognitive representation of myocardial infraction. Research in Psychological Health. 2008;2(2):29-39. (Persian)

24. Davey GC, Wells A. Worry and its psychological disorders: Theory, assessment and treatment. New Jersey:John Wiley \& Sons;2006.

25. Dehshiri GR, Golzari M, Borjali A, Sohrabi F. Psychometrics particularity of farsi version of Pennsylvania state worry questionnaire for college students. Journal of Clinical Psycology. 2009;1(4):67-75. (Persian)

26. Ebrahimi Moghadam H, Malmir T, Rahmani F, Ramezan Alizadeh Z. Investigate the effectiveness of group training based on Acceptance and Commitment Therapy (ACT) on aggression and anxiety in patients with panic. The Quarterly Journal of Psychological Studies. 2018;13(4):141-156. (Persian)

27. Baghban Baghestan A, Aerab Sheibani K, Javedani Masrur M. Acceptance and commitment based therapy on disease perception and psychological capital in patients with type II diabetes. Quarterly of Horizon of Medical Sciences. 2017;23(2):135140. (Persian)
28. Eifert GH, Heffner M. The effects of acceptance versus control contexts on avoidance of panic-related symptoms. Journal of Behavior Therapy and Experimental Psychiatry. 2003;34(3-4):293-312.

29. Sheydayi Aghdam S, Shamseddini Lory S, Abassi S, Yosefi, S, Abdollahi S, Moradijoo M. The effectiveness of treatment based on acceptance and commitment in reducing distress and inefficient attitudes in patients with MS. Journal of Thought \& Behavior in Clinical Psychology. 2014;9(37):57-66. (Persian) 30. Mahdavi A, Aghaei M, Aminnasab V, Tavakoli Z, Besharat M, Abedin M. The effectiveness of acceptance-commitment therapy (ACT) on perceived stress, symptoms of depression, and marital satisfaction in women with breast cancer. Archives of Breast Cancer. 2017:4(1)16-23.

31. Khaleghi M, Mohammadkhani Sh, Hasani J. Effectiveness of emotional schema therapy in reduction of worry and anxiety's signs and symptoms in patients with generalized anxiety disorder: Single-subject design. Journal of Clinical Psychology. 2016;8(2):43-55. (Persian)

32. Fassbinder E, Arntz A. Schema therapy with emotionally inhibited and fearful patients. Journal of Contemporary Psychotherapy. 2019;49(1):7-14.

33. Ghorbanalipoor M, Moghadamzadeh A, Jafary E. The effectiveness of schema therapy and logo therapy on death anxiety in patients with hypochondriasis. Research in Clinical Psychology and Counseling. 2017;7(1):52-66. (Persian)

34. Brand-de Wilde O, Arntz A. Schema Therapy. In: Dobson K, Dozois D, editors. Handbook of cognitive-behavioral therapies. 4th ed. New York:Guilford Press;2019. p. 249.

35. Yakushko O. Don’t worry, be happy: Erasing racism, sexism, and poverty in positive psychology. Psychotherapy and Politics International. 2018;16(1):e1433. 